\title{
Chryseobacterium piperi sp. nov., isolated from a freshwater creek
}

\author{
Correspondence \\ Jeffrey D. Newman \\ newman@lycoming.edu
}

\author{
Brittane L. Strahan, ${ }^{\dagger}$ Kevin C. Failor, Allison M. Batties, ${ }^{\ddagger}$ Patrick S. Hayes, ${ }^{\S}$ \\ Kellie M. Cicconi," Christopher T. Mason and Jeffrey D. Newman
}

Biology Department, Lycoming College, Williamsport, PA 17701, USA
The number of species with validly published names within the genus Chryseobacterium has increased dramatically in recent years. The genus was first described by Vandamme et al. (1994) with six species but when the description of the family Flavobacteriaceae was emended by Bernardet et al. (2002), there had been no novel validly published additions. Since that time, however, more than 40 novel species of the genus Chryseobacterium have been identified

tPresent Address: Thomas Jefferson University School of Nursing, Geisinger Hospital, 100 North Academy Ave, Danville, PA 17822, USA.

$\ddagger$ Present Address: Department of Molecular Medicine, University of Virginia, Charlottesville, VA 22908-0735, USA.

§Present Address: Skirball Institute of Biomolecular Medicine, NYU Langone Medical Center, 540 First Ave, New York, NY 10016, USA.

|lPresent Address: Department of Population Medicine and Diagnostic Sciences, Cornell University, Ithaca, NY 14850, USA.

- Present Address: AECOM Technical Services Inc., 2 Market Plaza Way, Mechanicsburg, PA 17050, USA.

The GenBank/EMBL/DDBJ accession number for the 16S rRNA gene sequence of strain CTM $^{\top}$ is EU999735. GenBank/EMBL/DDBJ accession numbers for the gyrB gene sequences of strains $\mathrm{CTM}^{\top}$, Chryseobacterium soldanellicola DSM $17072^{\top}$, Chryseobacterium soli DSM 19298', Chryseobacterium shigense DSM $17076^{\top}$ and Chryseobacterium luteum DSM 18605 ${ }^{\top}$ are HQ011910, HO011912, HQ011913, HQ011911 and HQ011909, respectively.

Two supplementary figures and two supplementary tables are available with the online version of this paper. from a variety of sources, including a water reservoir (Kim et al., 2008), cow's milk (Hantsis-Zacharov et al., 2008), diseased fish (Ilardi et al., 2009), arthropod faeces (Kämpfer et al., 2010) and many other environments (Bernardet et al., 2006).

For decades, most undergraduate microbiology courses have included a series of experiments in which students must identify an unknown microbe. Over the past decade, the availability of universal primers for the amplification of $16 \mathrm{~S}$ rRNA gene sequences and inexpensive DNA sequencing services have allowed students to identify truly novel organisms, as yet unknown to science, from the environment (Newman, 2000). Given that a significant percentage of culturable organisms have not yet been described in taxonomic literature, it is not surprising that novel organisms are encountered in these lab courses. Here, we describe a polyphasic study of one such organism.

Samples of sediment and water were obtained in January, 2006, from Loyalsock Creek $\left(41.488^{\circ} \mathrm{N} 76.600^{\circ} \mathrm{W}\right)$, near Forksville, North-central Pennsylvania. After vigorous resuspension and the settling of large particulates, aqueous samples were serially diluted in tryptic soy broth (TSB; Remel) and spread on tryptic soy broth agar (TSBA) plates containing $16 \mathrm{~g}$ agar (Teknova) per $1 \mathrm{TSB}$. Well-separated colonies were selected and purified by streak plating for analysis by the students. Isolates were grown at $30{ }^{\circ} \mathrm{C}$ for 2 days unless otherwise noted, and permanent stocks were 
maintained at $-80{ }^{\circ} \mathrm{C}$ in TSB supplemented with $20 \%$ glycerol. For subsequent comparative studies, Chryseobacterium soli DSM $19298^{\mathrm{T}}$ (Weon et al., 2008), Chryseobacterium soldanellicola DSM $17072^{\mathrm{T}}$ (Park et al., 2006), Chryseobacterium shigense DSM $17076^{\mathrm{T}}$ (Shimomura et al., 2005) and Chryseobacterium luteum DSM $18605^{\mathrm{T}}$ (Behrendt et al., 2007) were purchased from the DSMZ and used as reference strains after confirming their identity by $16 \mathrm{~S}$ rRNA sequencing as described below.

DNA was isolated for analysis using a Qiagen Blood and Tissue kit. DNA G $+\mathrm{C}$ content was determined by the method of Mesbah et al. (1989) using a $4.6 \times 150 \mathrm{~mm}$ Zorbax Eclipse Plus C18 column ( $3.5 \mu \mathrm{m}$ particle size) (Agilent) on an Agilent 1200 liquid chromatograph. The DNA $\mathrm{G}+\mathrm{C}$ content of strain $\mathrm{CTM}^{\mathrm{T}}$ was $38.6 \mathrm{~mol} \%$ and those of reference strains C. soli DSM $19298^{\mathrm{T}}$ and C. soldanellicola DSM $17072^{\mathrm{T}}$ were 39.5 and $38.9 \mathrm{~mol} \%$, respectively. While these values are in line with those previously reported for C. soli DSM $19298^{\mathrm{T}}$ (39.9 mol\%; Weon et al., 2008) and many other strains of the genus Chryseobacterium (Weon et al., 2008; Kim et al., 2008; Park et al., 2008; Herzog et al., 2008), the value of $38.9 \mathrm{~mol} \%$ obtained for C. soldanellicola DSM $17072^{\mathrm{T}}$ was significantly higher in this study than the value of $28.8 \mathrm{~mol} \%$ reported by Park et al. (2006) for this strain. This higher value is, however, consistent with the DNA G $+\mathrm{C}$ content of the gyrB gene fragment $(38.1 \mathrm{~mol} \%)$ as described below, as well as the that of groEL/cpn60 and $r p o B$ gene fragments (unpublished results). No other strains of the genus Chryseobacterium are reported to have DNA G+C contents below $30 \mathrm{~mol} \%$.

Primers 27f and 1492r (Lane, 1991) were used to amplify the $16 \mathrm{~S}$ rRNA gene of strain $\mathrm{CTM}^{\mathrm{T}}$ using high fidelity ExTaq DNA polymerase (Takara) and the following PCR conditions: 1 cycle of $94{ }^{\circ} \mathrm{C}$ for $3 \mathrm{~min} ; 30$ cycles of $94{ }^{\circ} \mathrm{C}$ for $45 \mathrm{~s}, 50{ }^{\circ} \mathrm{C}$ for $45 \mathrm{~s}, 72{ }^{\circ} \mathrm{C}$ for $1 \mathrm{~min}$; followed by a final extension step of $72{ }^{\circ} \mathrm{C}$ for $5 \mathrm{~min}$. PCR product (1477 bp) purification and sequencing were performed by Agencourt/ Beckman-Coulter Genomics using primers 27f, 357f, 785f, 1119f, 1492r and 810r (Lane, 1991). Reads were assembled using the CAP3 sequence assembly program (http://pbil. univ-lyon1.fr/cap3.php; Huang \& Madan, 1999).

Identification of phylogenetic neighbours and calculation of pairwise 16S rRNA gene sequence similarities were performed using the EzTaxon server (http://www.eztaxon. org/; Chun et al., 2007). Sequences of other species of the genus Chryseobacterium were downloaded from EzTaxon and aligned to the seed alignment by the Ribosomal Database Project (RDP) (Cole et al., 2007, 2009); Elizabethkingia meningoseptica was used as an outgroup. Weighted neighbour-joining (Bruno et al., 2000) trees inferred from the alignment (Fig. 1; Supplementary Fig. S1, available in IJSEM Online) using the RDP Tree-Builder program with 1000 resamplings to measure bootstrap support (Felsenstein, 1985), were compared to trees produced in the MEGA4 program (Tamura et al., 2007)

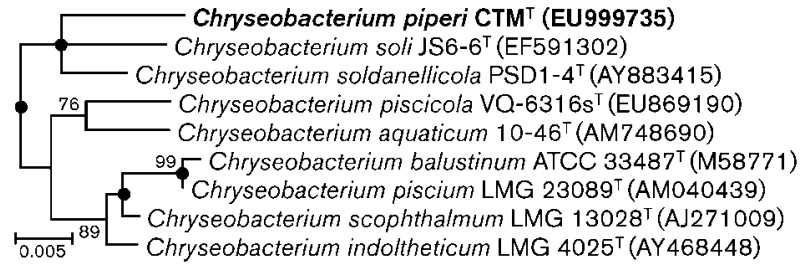

Fig. 1. Neighbour-joining phylogenetic tree based on $16 \mathrm{~S}$ rRNA gene sequences showing the phylogenetic relationship between strain CTM $^{\top}$ and closely related species of the genus Chryseobacterium. Elizabethkingia meningoseptica ATCC $13253^{\top}$ (AJ704540) was used as an outgroup (not shown). Bootstrap values $>70 \%$ (expressed as percentages of 1000 replications) are given at branch nodes. Dots indicate branch nodes that were also present in either the maximum-likelihood or maximum-parsimony trees. Bar, 0.005 substitutions per nucleotide position.

using the maximum-likelihood and maximum-parsimony methods (Nei \& Kumar, 2000). A similar topology, grouping strain $\mathrm{CTM}^{\mathrm{T}}$ with $C$. soldanellicola PSD1-4 ${ }^{\mathrm{T}}$ and C. soli JS6- $6^{\mathrm{T}}$ was obtained in all three instances, as indicated by filled circles on the neighbour-joining trees. The 16S rRNA gene sequence of strain $\mathrm{CTM}^{\mathrm{T}}$ was similar to that of C. soldanellicola PSD $1-4^{\mathrm{T}}(97.3 \%)$, C. soli JS6- $6^{\mathrm{T}}$, $(96.8 \%)$ and those of other species of the genus Chryseobacterium (92.6-96.7\%). These values were well below the 98.7-99.0\% similarity threshold corresponding to a DNA-DNA hybridization value of $70 \%$ (Stackebrandt \& Ebers, 2006). However, as an additional means to demonstrate genomic uniqueness and to improve the resolution with which we could distinguish the species genetically, we analysed the sequence of the gyrB gene encoding subunit B of DNA gyrase.

GyrB amino acid sequences were derived from genomic sequences of a variety of species of the phylum Bacteroidetes present in GenBank, including Chryseobacterium gleum (accession no. NZ_ACKQ02000000), and were aligned to identify conserved sequences for the design of the degenerate primers GyrB-350aaF (5'-CARTTYGARGGNCARCANAA-3') and GyrB-600aaR (5'-TTCATYTCNCCNARNCCYTTRTA-3'). A $~ 750$ bp fragment was amplified by PCR from a variety of species of the phylum Bacteroidetes using the same cycling conditions as those used to amplify $16 \mathrm{~S}$ rRNA gene sequences, except that the annealing temperature was increased to $55{ }^{\circ} \mathrm{C}$ for the first five cycles to improve specificity.

The gyrB sequences generated in this study with strain $\mathrm{CTM}^{\mathrm{T}}$ and the four reference strains were aligned in the GenBank database with sequences of other Flavobacteriaceae gyrB genes using the CLUSTAL w program in MEGA 4. The alignment was manually edited and used to reconstruct neighbour-joining (Supplementary Fig. S2), maximumlikelihood and maximum-parsimony trees (complete deletion option). All of the Chryseobacterium gyrB sequences 
clustered together and the pairwise similarities between $\operatorname{gyr} B$ sequences of strain $\mathrm{CTM}^{\mathrm{T}}$ and other members of the genus Chryseobacterium (85.8-87.8\%) were less than the pairwise similarity value between $C$. gleum and $C$. indologenes $(88.6 \%)$ or between C. luteum and C. shigense $(89.5 \%)$. While comparing gyrB sequences and DNA-DNA hybridizations in other members of the family Flavobacteriaceae, specifically members of the genera Tenacibaculum and Cytophaga, Suzuki et al. (2001) noted that a $70 \%$ DNADNA hybridization level correlated with $g y r B$ gene sequence similarity values as low as $88.8 \%$ but, in most cases, similarity values were significantly higher.

Strain $\mathrm{CTM}^{\mathrm{T}}$ was initially characterized by visual observation of colony colour, texture and morphology, Gram stain reaction by the Hucker method (Gerhardt et al., 1994), endospore staining using the Schaeffer-Fulton method (Gerhardt et al., 1994) and motility in hanging drop wet mounts using bright-field microscopy. The metabolic characteristics of strain $\mathrm{CTM}^{\mathrm{T}}$, Chryseobacterium soli DSM $19298^{\mathrm{T}}$ and C. soldanellicola DSM $17072^{\mathrm{T}}$ were determined following the methods described by Gerhardt et al., (1994) unless otherwise noted. Examination of carbohydrate metabolism included testing for citrate utilization with Simmons citrate agar, acetoin production via the VoguesProskauer test and fermentative acid and gas production in a phenol-red broth base supplemented with $0.75 \%$ glucose, lactose, sucrose, mannitol, arabinose or galactose. Nitrogen metabolism studies included nitrate reduction tests using tryptic nitrate broth, indole and hydrogen sulfide production assays using SIM medium and the phenylalanine deaminase assay on phenylalanine agar. The requirement for oxygen was tested by growth on TSBA in a Gas-Pak jar made anaerobic by inclusion of an AnaeroPack pouch (Mitsubishi Gas Chemical). The presence of cytochrome oxidase was determined by smearing a freshly grown culture onto a filter paper disk and adding a few drops of oxidase reagent (Difco$\mathrm{BBL}$ ). The presence of catalase was detected by observing oxygen bubbles produced after submerging bacteria on a cotton swab into $3 \%$ hydrogen peroxide solution. Production of exoenzymes was determined after 2 days of growth on the following media: caseinase on skimmed milk agar, lecithinase on spirit blue agar supplemented with lipase reagent (Difco), amylase on starch agar that was flooded with Gram's iodine after growth, DNase on agar supplemented with $0.2 \%$ DNA that was flooded with $1 \mathrm{M} \mathrm{HCl}$ after growth, Tween 80 hydrolase on TSBA supplemented with $1 \%$ Tween 80 , gelatinase in nutrient broth supplemented with $12 \%$ gelatin, and haemolysis on BUG (Biolog) and TSA (Remel) media supplemented with $5 \%$ sheep's blood. Growth on Endo, EMB, MacConkey, phenylethanol and mannitol salt agars (Difco) as well as on lab prepared R2A (van der Linde et al., 1999) and cetrimide (Difco Manual, 1984) agars was also tested.

After initial screening suggested that strain $\mathrm{CTM}^{\mathrm{T}}$ might be a novel species of the genus Chryseobacterium, more extensive general tests and Flavobacteriaceae-specific tests were conducted on strain $\mathrm{CTM}^{\mathrm{T}}$ as well as on the reference strains C. soli DSM $19298^{\mathrm{T}}$ (Weon et al., 2008), and C. soldanellicola DSM $17072^{\mathrm{T}}$ (Park et al., 2006). All assays were repeated at least twice and metabolic profiles of the three strains were generated using GenIII plates (Biolog) incubated at $30{ }^{\circ} \mathrm{C}$, API $20 \mathrm{NE}$ strips incubated at $30{ }^{\circ} \mathrm{C}$ and API ZYM test strips (bioMérieux) incubated at $37^{\circ} \mathrm{C}$ according to the manufacturers' instructions (see Table 1 and Supplementary Tables S1 and S2). Growth temperature requirements were tested on TSA plates at 5, 20, 30, 37 and $45{ }^{\circ} \mathrm{C}$. Tolerance of $\mathrm{NaCl}$ was determined in $\mathrm{NaCl}-$ free TSB supplemented with $0,1,2,3,4,5$ or $6 \%(\mathrm{w} / \mathrm{v})$ $\mathrm{NaCl}$. Growth at pH 4.0, 5.0, 5.5, 6.0, 6.5, 7.0, 7.5, 8.0, 8.5, 9.0 and 10.0 was determined in TSB adjusted with either $\mathrm{HCl}$ or $\mathrm{NaOH}$ and retested with $\mathrm{pH}$ paper after autoclaving. For $\mathrm{NaCl}$ and $\mathrm{pH}$ tolerance studies, cells were incubated in the shaker and growth was monitored spectrophotometrically at $\mathrm{OD}_{600}$ for $48 \mathrm{~h}$. The presence of flexirubin-type pigments was determined by the red colour shift response in the presence of $20 \% \mathrm{KOH}$ (Bernardet et al., 2002) and respiratory quinones were

Table 1. Phenotypic characteristics of strain $\mathrm{CTM}^{\top}$ and closely related species of the genus Chryseobacterium

Strains: $1, \mathrm{CTM}^{\mathrm{T}} ; 2$, C. soli DSM $19298^{\mathrm{T}} ; 3$, C. soldanellicola DSM $17072^{\mathrm{T}}$. + , Positive; w, weakly positive; - , negative. All data from this study.

\begin{tabular}{|c|c|c|c|}
\hline Characteristic & 1 & 2 & 3 \\
\hline Growth on cetrimide agar & + & + & - \\
\hline Growth on Endo agar & + & $\mathrm{W}$ & - \\
\hline DNase activity & + & + & - \\
\hline$\beta$-Haemolysis & + & - & - \\
\hline \multicolumn{4}{|l|}{ API 20 NE strip } \\
\hline Urease & + & + & - \\
\hline PNPG hydrolysis & + & - & - \\
\hline \multicolumn{4}{|l|}{ Utilization of (GenIII plate): } \\
\hline Dextrin & + & + & - \\
\hline Sucrose & + & + & - \\
\hline$\alpha$-D-Glucose & + & + & - \\
\hline D-Mannitol & + & - & - \\
\hline Glycerol & + & + & - \\
\hline D-Glucose-6-phosphate & + & - & $\mathrm{w}$ \\
\hline D-Fructose-6-phosphate & + & - & $\mathrm{w}$ \\
\hline D-Aspartic acid & + & - & - \\
\hline L-Pyroglutamic acid & + & - & - \\
\hline L-Serine & + & + & - \\
\hline D-Glucuronic acid & + & - & $\mathrm{w}$ \\
\hline Citric acid & + & - & - \\
\hline Tween 40 & + & + & - \\
\hline Acetoacetic acid & + & $\mathrm{w}$ & - \\
\hline Formic acid & + & - & - \\
\hline \multicolumn{4}{|l|}{ Resistance to (GenIII plate): } \\
\hline Rifamycin SV & + & - & + \\
\hline Lincomycin & $\mathrm{w}$ & - & + \\
\hline \multicolumn{4}{|l|}{ Reduction of (GenIII plate): } \\
\hline Tetrazolium violet & + & - & - \\
\hline
\end{tabular}


analysed by TLC using the method of Komagata \& Suzuki (1987). Fatty acid profiles were determined by GLC (MIDI Sherlock version 6.1, method RTSBA6) using cells grown on TSBA for $24 \mathrm{~h}$ at $30{ }^{\circ} \mathrm{C}$ and extracted using the standard method of Sasser (1990). The fatty acid composition of strain $\mathrm{CTM}^{\mathrm{T}}$ (Table 2) was typical of species of the genus Chryseobacterium (Bernardet et al., 2006) in that the most abundant fatty acids were iso- $\mathrm{C}_{15: 0}$, iso- $\mathrm{C}_{17: 1} \omega 9 c$, iso- $\mathrm{C}_{17: 0}$ 3-OH and summed feature 3 (comprising $\mathrm{C}_{16: 1} \omega 6 c / \mathrm{C}_{16: 1} \omega 7 c /$ iso- $\left.\mathrm{C}_{15: 0} \quad 2-\mathrm{OH}\right)$. Other biochemical characteristics of strain $\mathrm{CTM}^{\mathrm{T}}$ are listed in the species description, while phenotypes that can be used to distinguish strain $\mathrm{CTM}^{\mathrm{T}}$ from related species are listed in Table 1 . The combination of phenotypic and genotypic characteristics that differentiate strain $\mathrm{CTM}^{\mathrm{T}}$ from previously described species suggests that strain $\mathrm{CTM}^{\mathrm{T}}$ represents a novel species of the genus Chryseobacterium, for which the name Chryseobacterium piperi sp. nov. is proposed.

\section{Description of Chryseobacterium piperi sp. nov.}

Chryseobacterium piperi (pi'per.i. N.L. gen. masc. piperi of Piper, in honour of John F. Piper Jr, recently retired Academic Dean of Lycoming College).

Cells are strictly aerobic, non-spore-forming, non-motile Gram-reaction-negative rods, $0.5 \times 3 \mu \mathrm{m}$. Grows on R2A, tryptic soy, Endo and cetrimide agars, but not on MacConkey, EMB, phenylethanol or mannitol-salt agars. Colonies on TSA are translucent and shiny with entire edges. Yellow-orange non-diffusible flexirubin-type pigments are produced. Grows well at $20-30{ }^{\circ} \mathrm{C}$ and weakly at $37{ }^{\circ} \mathrm{C}$, but

Table 2. Cellular fatty acid profiles (\%) of strain $\mathrm{CTM}^{\top}$ and closely related species of the genus Chryseobacterium

Strains: $1, \mathrm{CTM}^{\mathrm{T}} ; 2$, C. soli DSM $19298^{\mathrm{T}} ; 3$, C. soldanellicola DSM $17072^{\mathrm{T}} \cdot \operatorname{tr}=$ Trace $(<1 \%)$; fatty acids amounting to $<1 \%$ of the total fatty acids in all three strains are not shown. All strains were grown on TSBA at $30{ }^{\circ} \mathrm{C}$ for $24 \mathrm{~h}$. All data from this study.

\begin{tabular}{|lccc|}
\hline Fatty acid & $\mathbf{1}$ & $\mathbf{2}$ & $\mathbf{3}$ \\
\hline iso- $_{13: 0}$ & 1.1 & 1.0 & 1.8 \\
iso- $\mathrm{C}_{15: 0}$ & 36.6 & 36.5 & 40.4 \\
anteiso- $\mathrm{C}_{15: 0}$ & $\operatorname{tr}$ & 2.6 & 2.7 \\
Summed feature $3^{*}$ & 12.6 & 11.9 & 11.8 \\
$\mathrm{C}_{16: 0}$ & 1.1 & 1.6 & 1.4 \\
iso- $\mathrm{C}_{15: 0} 3-\mathrm{OH}$ & 4.2 & 2.8 & 3.6 \\
iso- $\mathrm{C}_{17: 1} \omega 9 \mathrm{c}$ & 22.0 & 16.9 & 12.2 \\
iso- $\mathrm{C}_{17: 0}$ & $\operatorname{tr}$ & 1.3 & $\operatorname{tr}$ \\
$\mathrm{C}_{16: 0} 3-\mathrm{OH}$ & 1.8 & 1.3 & 1.6 \\
iso- & 17.9 & 20.7 & 19.8 \\
$\mathrm{C}_{17: 0}$ 2-OH & $\operatorname{tr}$ & 1.1 & $\operatorname{tr}$ \\
\hline
\end{tabular}

*Summed features are groups of two or three fatty acids that cannot be separated by GLC using the MIDI system. Summed feature 3 comprises $\mathrm{C}_{16: 1} \omega 6 c, \mathrm{C}_{16: 1} \omega 7 c$ and/or iso- $\mathrm{C}_{15: 0} 2-\mathrm{OH}$. not at $5{ }^{\circ} \mathrm{C}$ or $42{ }^{\circ} \mathrm{C}$. The $\mathrm{pH}$ range for growth is $\mathrm{pH} 6-10$ (optimum $\mathrm{pH}$ 6.5-8.0). Grows in the presence of $0-2 \%$ $(\mathrm{w} / \mathrm{v}) \mathrm{NaCl}$, but not in $3 \% \mathrm{NaCl}$. Cells produce indole on SIM medium and exhibit oxidase, catalase, amylase, caseinase, DNase, gelatinase, Tween 80 hydrolase and $\beta$-haemolytic activities. Negative for phenylalanine deaminase and lipase activities, nitrate reduction, utilization of citrate, production of hydrogen sulfide and acetoin and production of acid from fermentation of glucose, lactose, sucrose, mannitol, arabinose and galactose. In the API $20 \mathrm{NE}$ system; positive for indole production and hydrolysis of urea, aesculin, gelatin and PNPG but negative for nitrate reduction, production of acid from D-glucose, arginine dihydrolase activity and the utilization of L-arabinose, $\mathrm{N}$-acetylglucosamine, gluconic acid, capric acid, adipic acid, malic acid, trisodium citrate and phenylacetic acid. Weakly utilizes $\alpha$-D-glucose, D-mannose, D-mannitol, and maltose. In the API ZYM system; positive for alkaline phosphatase, C4 esterase (weakly), C8 esterase lipase, leucine-, valine-, and cystine (weakly) arylamidase, acid phosphatase, naphthol-AS-BI-phosphohydrolase, $\alpha$-glucosidase and $N$ acetyl- $\beta$-glucosaminidase activities; negative for lipase (C14), trypsin, $\alpha$-chymotrypsin, $\alpha$ - and $\beta$-galactosidase, $\beta$-glucuronidase, $\beta$-glucosidase, $\alpha$-mannosidase and $\alpha$ fucosidase activities. On the GenIII plate; positive for utilization of dextrin, maltose, trehalose, gentiobiose, sucrose, $\alpha$-D-glucose, D-mannose, D-fructose, D-mannitol, glycerol, D-glucose-6-phosphate, D-fructose-6-phosphate, D-aspartic acid, gelatin, glycyl-L-proline, L-aspartic acid, L-glutamic acid, L-pyroglutamic acid, L-serine, pectin, D-galacturonic acid, D-glucuronic acid, citric acid, Tween40, acetoacetic acid, acetic acid and formic acid; weakly positive for utilization of D-galactose, 3-methyl glucose, D- and L-fucose, L-rhamnose, L-alanine, mucic acid, quinic acid, D-lactic acid methyl ester and $\alpha$-keto-glutaric acid; negative for the remaining utilization tests. Also on the GenIII plate; resistant to $\mathrm{pH} 6,1 \% \mathrm{NaCl}, 1 \% \mathrm{Na}$-lactate, rifamycin SV and aztreonam; weakly resistant to D-serine, lincomycin, guanidine $\mathrm{HCl}$, and K-tellurite; sensitive to the remaining inhibitory conditions. Tetrazolium blue and tetrazolium violet are reduced. The major fatty acids are iso- $\mathrm{C}_{15: 0}$, iso- $\mathrm{C}_{17: 1} \omega 9 c$, iso- $\mathrm{C}_{17: 0} 3-\mathrm{OH}$ and summed feature 3 (comprising $\mathrm{C}_{16: 1} \omega 6 c, \mathrm{C}_{16: 1} \omega 7 c$ and/or iso- $\mathrm{C}_{15: 0}$ 2-OH). Menaquinone MK-6 is the predominant respiratory quinone.

The type strain, CTM $^{\mathrm{T}}\left(=\right.$ ATCC BAA- $1782^{\mathrm{T}}=$ CCUG $57707^{\mathrm{T}}=$ JCM $15960^{\mathrm{T}}=$ DSM $22249^{\mathrm{T}}=$ KCTC $23267^{\mathrm{T}}$ ), was isolated from a freshwater creek in North-central Pennsylvania, USA. The DNA G $+\mathrm{C}$ content of the type strain is $38.6 \mathrm{~mol} \%$.

\section{Acknowledgements}

B.L.S. and K.C.F. were supported by summer undergraduate research fellowships from the American Society for Microbiology. Biolog, MIDI-MIS and HPLC instruments were purchased through NSF funding (DBI-0960114) awarded to J.D.N. 


\section{References}

Behrendt, U., Ulrich, A., Spröer, C. \& Schumann, P. (2007). Chryseobacterium luteum sp. nov., associated with the phyllosphere of grasses. Int J Syst Evol Microbiol 57, 1881-1885.

Bernardet, J.-F., Nakagawa, Y., Holmes, B. \& Subcommittee on the taxonomy of Flavobacterium and Cytophaga-like bacteria of the International Committee on Systematics of Prokaryotes (2002). Proposed minimal standards for describing new taxa of the family Flavobacteriaceae and emended description of the family. Int J Syst Evol Microbiol 52, 1049-1070.

Bernardet, J.-F., Hugo, C. \& Bruun, B. (2006). The genera Chryseobacterium and Elizabethkingia. In The Prokaryotes: a Handbook on the Biology of Bacteria, 3rd edn, vol. 7, pp. 638-676. Edited by M. Dworkin, S. Falkow, E. Rosenberg, K. H. Schleifer \& E. Stackebrandt. New York: Springer.

Bruno, W. J., Socci, N. D. \& Halpern, A. L. (2000). Weighted neighbor joining: a likelihood-based approach to distance-based phylogeny reconstruction. Mol Biol Evol 17, 189-197.

Chun, J., Lee, J.-H., Jung, Y., Kim, M., Kim, S., Kim, B. K. \& Lim, Y. W. (2007). EzTaxon: a web-based tool for the identification of prokaryotes based on $16 \mathrm{~S}$ ribosomal RNA gene sequences. Int J Syst Evol Microbiol 57, 2259-2261.

Cole, J. R., Chai, B., Farris, R. J., Wang, Q., Kulam-Syed-Mohideen, A. S., McGarrell, D. M., Bandela, A. M., Cardenas, E., Garrity, G. M. \& Tiedje, J. M. (2007). The ribosomal database project (RDP-II): introducing $m y R D P$ space and quality controlled public data. Nucleic Acids Res 35 (Database issue), D169-D172.

Cole, J. R., Wang, Q., Cardenas, E., Fish, J., Chai, B., Farris, R. J., Kulam-Syed-Mohideen, A. S., McGarrell, D. M., Marsh, T. \& other authors (2009). The Ribosomal Database Project: improved alignments and new tools for rRNA analysis. Nucleic Acids Res 37 (Database issue), D141-D145.

Felsenstein, J. (1985). Confidence limits on phylogenies: an approach using the bootstrap. Evolution 39, 783-791.

Gerhardt, P., Murray, R. G. E., Wood, W. A. \& Krieg, N. R. (editors) (1994). Methods for General and Molecular Bacteriology. Washington, DC: American Society for Microbiology.

Hantsis-Zacharov, E., Shakéd, T., Senderovich, Y. \& Halpern, M. (2008). Chryseobacterium oranimense sp. nov., a psychrotolerant, proteolytic and lipolytic bacterium isolated from raw cow's milk. Int $J$ Syst Evol Microbiol 58, 2635-2639.

Herzog, P., Winkler, I., Wolking, D., Kämpfer, P. \& Lipski, A. (2008). Chryseobacterium ureilyticum sp. nov., Chryseobacterium gambrini sp. nov., Chryseobacterium pallidum sp. nov. and Chryseobacterium molle sp. nov., isolated from beer-bottling plants. Int J Syst Evol Microbiol 58, 26-33.

Huang, X. \& Madan, A. (1999). CAP3: a DNA sequence assembly program. Genome Res 9, 868-877.

llardi, P., Fernández, J. \& Avendaño-Herrera, R. (2009). Chryseobacterium piscicola sp. nov., isolated from diseased salmonid fish. Int J Syst Evol Microbiol 59, 3001-3005.

Kämpfer, P., Arun, A. B., Young, C.-C., Chen, W.-M., Sridhar, K. R. \& Rekha, P. D. (2010). Chryseobacterium arthrosphaerae sp. nov., isolated from the faeces of the pill millipede Arthrosphaera magna Attems. Int J Syst Evol Microbiol 60, 1765-1769.

Kim, K. K., Lee, K. C., Oh, H.-M. \& Lee, J. S. (2008). Chryseobacterium aquaticum sp. nov., isolated from a water reservoir. Int J Syst Evol Microbiol 58, 533-537.

Komagata, K. \& Suzuki, K. (1987). Lipid and cell-wall analysis in bacterial systematics. Methods Microbiol 19, 161-207.

Lane, D. J. (1991). 16S/23S rRNA Sequencing. Nucleic Acid Techniques in Bacterial Systematics, pp. 115-175. Edited by E. Stackebrandt \& M. Goodfellow. New York, NY: John Wiley and Sons.

Mesbah, M., Premachandran, U. \& Whitman, W. B. (1989). Precise measurement of the $\mathrm{G}+\mathrm{C}$ content of deoxyribonucleic acid by highperformance liquid chromatography. Int J Syst Bacteriol 39, 159-167.

Nei, M. \& Kumar, S. (2000). Molecular Evolution and Phylogenetics. New York: Oxford University Press.

Newman, J. D. (2000). Molecular phylogeny in the undergraduate microbiology laboratory. Focus on Microbiol Educ 6, 3-4.

Park, M. S., Jung, S. R., Lee, K. H., Lee, M. S., Do, J. O., Kim, S. B. \& Bae, K. S. (2006). Chryseobacterium soldanellicola sp. nov. and Chryseobacterium taeanense sp. nov., isolated from roots of sand-dune plants. Int J Syst Evol Microbiol 56, 433-438.

Park, S. C., Kim, M. S., Baik, K. S., Kim, E. M., Rhee, M. S. \& Seong, C. N. (2008). Chryseobacterium aquifrigidense sp. nov., isolated from a water-cooling system. Int J Syst Evol Microbiol 58, 607-611.

Sasser, M. (1990). Identification of bacteria by gas chromatography of cellular fatty acids. Technical Note no. 101. Newark, DE: MIDI Inc.

Shimomura, K., Kaji, S. \& Hiraishi, A. (2005). Chryseobacterium shigense sp. nov., a yellow-pigmented, aerobic bacterium isolated from a lactic acid beverage. Int J Syst Evol Microbiol 55, 1903-1906.

Stackebrandt, E. \& Ebers, J. (2006). Taxonomic parameters revisited: tarnished gold standards. Microbiol Today 33, 152-155.

Suzuki, M., Nakagawa, Y., Harayama, S. \& Yamamoto, S. (2001). Phylogenetic analysis and taxonomic study of marine Cytophaga-like bacteria: proposal for Tenacibaculum gen. nov. with Tenacibaculum maritimum comb. nov. and Tenacibaculum ovolyticum comb. nov., and description of Tenacibaculum mesophilum sp. nov. and Tenacibaculum amylolyticum sp. nov. Int J Syst Evol Microbiol 51, 1639-1652.

Tamura, K., Dudley, J., Nei, M. \& Kumar, S. (2007). MEGA4: molecular evolutionary genetics analysis (MEGA) software version 4.0. Mol Biol Evol 24, 1596-1599.

van der Linde, K., Lim, B. T., Rondeel, J. M., Antonissen, L. P. \& de Jong, G. M. (1999). Improved bacteriological surveillance of haemodialysis fluids: a comparison between Tryptic soy agar and Reasoner's 2A media. Nephrol Dial Transplant 14, 2433-2437.

Vandamme, P., Bernardet, J.-F., Segers, P., Kersters, K. \& Holmes, B. (1994). New perspectives in the classification of the flavobacteria: description of Chryseobacterium gen. nov., Bergeyella gen. nov., and Empedobacter nom. rev. Int J Syst Bacteriol 44, 827-831.

Weon, H. Y., Kim, B. Y., Yoo, S. H., Kwon, S. W., Stackebrandt, E. \& Go, S. J. (2008). Chryseobacterium soli sp. nov. and Chryseobacterium jejuense sp. nov., isolated from soil samples from Jeju, Korea. Int J Syst Evol Microbiol 58, 470-473. 